\title{
Improve the local search using Automatic Modified Position in Improved Spider Monkey Optimization Algorithm

\author{
Arti Bhuguna, Vinay Prasad Tamta
}

\begin{abstract}
Spider Monkey Optimization is the new field of Swarm Intelligence. The SMO algorithms well balanced for a good exploration. Algorithm based on Spider's extraordinary behavior. Monkeys the SMO algorithm is a population-based meta-heuristic. So these articles present automatic modifying the position of the local search to improve its position. Then we say the updating algorithm called Improved Spider Monkey Optimization algorithm. Using this alternative technique we improve speed convergence. Also this algorithm tested on the problems of reference. The research paper shows proposes a productive variant of SMO that improves the Number of function. Here we have some equations to resolve these problems also we compare the result between SMO and new ISMO.
\end{abstract}

Key words: SMO, ISMO, Modified position.

Keywords : ISMO, Modified position, SMO.

\section{INTRODUCTION}

The SMO algorithm is developed by J. C. Bansal et al. The purpose of this algorithm is to increases the intelligent social behavior of spider monkeys to searching the food sources. This type of algorithm apply the structure of fission- fussion. The social life of spider monkey is to discovering for the most popular food sources [1]. This type of algorithm is newly young so therefore there is not too much work present in the literature. This algorithm is used for several purposes like image segmentation and a new multilevel threshold approach to segmentation for grayscale images. According to Leonard-Jones problems the SMO algorithms is to maintain the right balance between Exploration and exploitation [2]. We use this algorithm in the search of the optimal solution. We use exploitation to the purpose of the optimal local solution has been correctly traversed. Also to avoid the problem in excellent local area we use to explore the Global research. Now we say that SMO is able to explore local research. The recent tendency of research goes towards algorithms inspired by nature Solve complex problems in the real world that cannot be solved with classical techniques. Now we assumed that the monkeys are younger also they are

Revised Manuscript Received on October 30, 2019.

* Correspondence Author

Arti Bahuguna*, IT department, H.N.B Garhwal University, Srinagar Garhwal, Uttarakhand, India. artibahuguna999@gmail.com

Vinay Prasad Tamta, IT department, H.N.B Garhwal University, Srinagar Garhwal, Uttarakhand, India. vinayprasadtamta@gmail.com

(C) The Authors. Published by Blue Eyes Intelligence Engineering and Sciences Publication (BEIESP). This is an open access article under the CC BY-NC-ND license (http://creativecommons.org/licenses/by-nc-nd/4.0/) more interacting with each other and often they randomly change their position in contrast to older monkeys [3].

Now adding the latest technique of SMO included a new local research. That is local research based on the law of power. This new strategy has been introduced to solve the Problem of reducing the older order of the model. The Fitness based on SMO Update or modifies the position of the current swarm based on its physical state [4]. It should be highly the adapted solution has a good solution in its vicinity.

\section{A. Spider Monkey Optimization}

The SMO follows the strategy of mimics the fission fusion structure. The SMO follows the some important characteristics of the structure. Which are follows as: First is Fission Merger Social structure. In this structure, the animals survive in a group of from. These groups of form can be having forty to fifty monkeys. Those monkeys are divided into a subgroup to look for food. To searching the food is the purpose of the in order to reduce competition. Here the women who have the role of world leader to look for a re-search. Now the food source will work likely into the group. Those groups are divided into Small sub-group to searching the food freely. The woman who plays the role of local leader drives the sub-groups and also it's responsible for tracking a well-organize program to the supply path every time. Now they all groups' members communicate with each other. The members must maintain social connection in the task of stagnation.

\section{OVERVIEW OF SPIDER MONKEY OPTIMIZATION ALGORITHM}

This SMOA is motivated by the intelligent feeding behavior. The following properties like self-organization and the division of labor is acceptable by SMO algorithm. Also it's obtaining intelligent swarming behaviors from the natural world [5].

Plus comments: In this section firstly we have two leaders' names as local and global leaders. In the local leader phase all monkeys update their values by learning from the local leader and in the second leader which is global leader experience and subsequent steps of the SMO algorithms. Its mechanisms of encouraging criticism of self-organization are shown.

Minus comments: In this section we discuss above the limit of the local and global leader. Those limits provide negative comments which are helpful to local and global leaders make their own decisions. 
Fluctuations: In this section all group members are redirected. They redirected towards unlike directions to look for food sources and that's shows the characteristic fluctuations.

Multiple interactions: In this section all monkeys of global and local leaders phase are communicate with each other. So now they are showing multiple interaction properties.

Division of work: This phase is also most important phase in the SMO algorithm. In this section when we captured the global reader and they divide the groups into smaller sub-groups. These sub-groups are play role to search for food in order. This phenomenon is helpful to imitate the division of labor ownership of spider monkeys [6].

\section{A. Phases of SMO Algorithm}

It has 7 main phases. We describe each phases as follows:

\section{Initialize population}

Firstly, we initialize spider monkey population given by $\mathrm{N}$ in the SMO algorithm. Secondly, the initial population denoted by the $\mathrm{D}$ dimension. $S M_{\mathrm{i}}$ vector $(\mathrm{i}=1,2 \ldots \mathrm{N}) . \quad \mathrm{SM}_{\mathrm{i}}$ represents the population of spider's money. $\mathrm{SM}_{\mathrm{i}}$ starts as follows:

$\mathrm{SM}_{\mathrm{ij}}=\mathrm{SM}_{\text {minj }}+\mathrm{I}(0,1) *\left(\mathrm{SM}_{\operatorname{maxj}}-\mathrm{SM}_{\text {minj }}\right)$

Where $S_{i j}$ represents the ith food source in the swarm, $\mathrm{SM}_{\text {minj }}$ and $\mathrm{SM}_{\operatorname{maxj}}$ are the lower and uper limits of $\mathrm{SM}_{\mathrm{i}}$ in jth direction $\mathrm{j}$ respectively and $\mathrm{I}[0,1]$ is a Random number evenly distributed in the interval $[0,1]$

\section{Local Leader Phase (LLP)}

In the LLP modify the position of SMO. All position is modifying according the experiences of local and global members. Using greedy section approach the members used to compare the physical form of the new position and the current position. Location of the $\mathrm{K}^{\text {th }}$ group SM update equation as follows:

$\mathrm{SM}_{\text {newij }}=\mathrm{SM}_{\mathrm{ij}}+\mathrm{I}[0,1] *\left(\mathrm{LL}_{\mathrm{kj}}-\mathrm{SM}_{\mathrm{ij}}\right)+\mathrm{I}[-1,1] *\left(\mathrm{SM}_{\mathrm{rj}}-\right.$ $\left.\mathrm{SM}_{\mathrm{ij}}\right)$------------------(2)

Where $\mathrm{SM}_{\mathrm{ij}}$ represents the solution $\mathrm{i}$ in the dimension jth, $L L_{k j}$ indicates the jth Size of the position of the local parent company $\mathrm{k}^{\text {th }}$. $\mathrm{SM}_{\mathrm{rj}}$ denotes the $\mathrm{j}^{\text {th }}$ dimension of the $\mathrm{r}^{\text {th }}$ and $\mathrm{SM}$ which is selected randomly $\mathrm{i}^{\text {th }}$ group. Where $\mathrm{r}$ does not equal to i.

\section{Global Leader Phase (GLP)}

In the GLP, they begin as soon as LLP is fully completed. In this phase the updated position is based on the previous experiences. And those previous experiences are based on the members of global leader. Here we use the group of local members with the help of following equation.

$\mathrm{SM}_{\text {newij }}=\mathrm{SM}_{\mathrm{ij}}+\mathrm{I}(0,1) *\left(\mathrm{GL}_{\mathrm{j}}-\mathrm{SM}_{\mathrm{ij}}\right)+\mathrm{I}(-1,1) *\left(\mathrm{SM}_{\mathrm{rj}}-\mathrm{SM}_{\mathrm{ij}}\right)$, (3)

Where $\mathrm{GL}_{\mathrm{j}}$ corresponds to the $\mathrm{j}^{\text {th }}$ dimension of the position of the global leader and $j \in 1,2 \ldots D$ is randomly selected. At this time, the $\mathrm{SM}_{\mathrm{i}}$ Update your position based on probabilities $\left(\right.$ prob $\left._{i}\right)$. The probability is calculated by the physical fitness. We have some different methods to calculating the probability.

Here we use fitness function to calculate the probability. We use this function for its suitable quality. The calculation of eligibility must include the value of the function.

Prob $_{\mathrm{i}}=0.9 \times\left(\right.$ fitness $_{\mathrm{i}} / \mathrm{f}$ itness_max $)+0.1$

Here fitness $\mathrm{s}_{\mathrm{i}}$ is the fitness value of $\mathrm{i}^{\text {th }}$ and fitness $\max$ is the ultimate in fitness group.

\section{Local Leader Learning (LLL) phase}

In the LLL phase, we use greedy selection algorithm. We apply this algorithm to the group. The main task of this algorithm is to look for the fitness position. The values of fitness position are without equal in the group. Now the SM position is the updated position for LL. Also the value of local limit is increased by 1 when the LL is not updated.

\section{Global Leader Learning (GLL) phase}

In the GLL phase, we use voracious selection approach. Using this approach the GL is updated their position. So the updated positions of the GL are selected as the most suitable SM position and the values of updated positions for the same population. Then now it is verified that the GL position is updated or not. Also we say the value of the global limit count is increased by 1 when the GL position is not updated.

\section{Decision-making phase of local leaders (LLD)}

In the LLD phase, the decision task is done on the bases of the LL position. If value of the position is not modernized up to a threshold k, Limit of LL (LLlimit). In case of not changing the position values. It randomizes the position of LL randomly. Now we use the following equation to decide the position of LL.

$\mathrm{SM}_{\text {newij }}=\mathrm{SM}_{\mathrm{ij}}+\mathrm{I}(0,1)^{*}\left(\mathrm{SM}_{\mathrm{j}}-\mathrm{SM}_{\mathrm{ij}}\right)+\mathrm{I}(0,1) *\left(\mathrm{SM}_{\mathrm{ij}}-\right.$ $\mathrm{LL}_{\mathrm{kj}}$ ),-------------------(5)

So it is clear that the updated dimension of this SM is attracted towards the GL and also to rejects the LL.

\section{Global Leader Decision (GLD) phase}

In the GLD phase, the decision task is done on the bases of the position value of the GL. If the value of the position is not modernized up to a threshold k limit is known GLlimit. During these process GLD Create small sub-groups. According to this phase new sub-group are created by the local leaders. Here the new sub-groups using the LLL process.

\section{UPDATE THE AUTOMATIC MODIFIED POSITION IN ISMOA}

In the different field of swarm intelligence the spider monkey is the least algorithm. For the literature purpose there is a very little task present in this topic. Here we innovating the new ideas to improve the performance of SMOA. In the ISMO, we suggested some improvements. These improvements are work in the phase of local leaders of SMO. Here we updated the position of ISMO to take the average of the difference in the current Position. This suggested change accelerates convergence to Evaluate and increase reliability. Here we use this equation to the most suitable optimal solution.

$\mathrm{Y}_{\mathrm{ij}}=\mathrm{X}_{\mathrm{ij}}+\mathrm{M}_{\mathrm{ij}}\left(\mathrm{LL}_{\mathrm{kj}}-\mathrm{ISM}_{\mathrm{ij}}\right)+\mathrm{M}_{\mathrm{ij}}(\mathrm{SUM} /$ $\mathrm{SN}), \ldots \ldots \ldots \ldots \ldots \ldots \ldots \ldots(6)$

Where is it

$\mathrm{SUM}=\mathrm{SUM}+\mathrm{X}_{\mathrm{ij}}-\mathrm{X}_{\mathrm{kj}}$,

$\mathrm{M}_{\mathrm{ij}}=$ random number generated

ISM $_{\mathrm{ij}}$ indicates the $\mathrm{j}^{\text {th }}$ dimension of the $\mathrm{I}^{\text {th }}$ ISM, LL $\mathrm{L}_{\mathrm{kj}}$ shows the $j^{\text {th }}$ dimension of the leader $\mathrm{k}^{\text {th }}$ position of the local group. $\mathrm{SN}$ is the randomly generates the position for the food source. SUM is the mean of the difference for the current position and the randomly generated position. 


\section{AN IMPROVED LOCAL SEARCH USING IMPROVED SPIDER MONKEY OPTIMIZATION ALGORITHM}

Step 1. Initialize the community, the $L_{\text {limit }}$, the $G L_{\text {limit }}$ and the permutation rate (pr).

Step 2. Calculate physical fitness (means distance of the food sources).

Step 3. Using a greedy selection to select leaders (local and global)

Step 4. While (extermination criteria do not met) do

Step 5. To find the goal (food source),

a. Means generate new location to entire members of the group.

$\mathrm{SMnew}_{\mathrm{ij}}=\mathrm{SM}_{\mathrm{ij}}+\mathrm{I} 1 \times\left(\mathrm{LL}_{\mathrm{kj}}-\mathrm{SM}_{\mathrm{ij}}\right)+\mathrm{I} 2 \times\left(\mathrm{SM}_{\mathrm{rj}}-\mathrm{SMij}\right)$ $+\mathrm{I} 3\left(\mathrm{SM}_{\mathrm{rj}}-\mathrm{SM}_{\mathrm{ij}}\right)$ Here $\mathrm{I} 1 \in(0,1), \mathrm{I} 2 \in(-1,1)$, I3 decided by GSS

Step 6. Now we use wolverine selection process between the existing and the newly met location (upon fitness) and select the best.

Step 7. Calculate the probability $\mathrm{p}_{\mathrm{i}}$.

Prob $_{\mathrm{i}}=0.9 \times\left(\right.$ fitness $_{\mathrm{i}} /$ fitness_max $)+0.1$

Step 8. Now we create new location in all group members selected by $\mathrm{p}_{\mathrm{i}}$, with the help of automatic global experience. $\mathrm{SMnew}_{\mathrm{ij}}=\mathrm{SM}_{\mathrm{ij}}+\mathrm{I} 1 \times\left(\mathrm{GLj}-\mathrm{SM}_{\mathrm{ij}}\right)+\mathrm{I} 2 \times\left(\mathrm{SM}_{\mathrm{rj}}-\mathrm{SM}_{\mathrm{ij}}\right)$ GSS

Step 9. Then we update the value of LL and GL by applying the greedy selection process.

Step 10. If a LL group does not update his location after specific number of times (LLlimit), then he redirects all the group members for algorithmic feeding.

if $\mathrm{I}(0,1) \geq \mathrm{pr}$

SMnew $_{\mathrm{ij}}=\mathrm{SMmin}_{\mathrm{j}}+\mathrm{I} \times\left(\mathrm{SMmax}_{\mathrm{j}}-\mathrm{SMmin}_{\mathrm{j}}\right)$ Where $\mathrm{I} \in(0,1)$ else

SMnewij $=\mathrm{SM}_{\mathrm{ij}}+\mathrm{M} \times\left(\mathrm{GL}_{\mathrm{j}}-\mathrm{SM}_{\mathrm{ij}}\right)+\mathrm{M} \times\left(\mathrm{SM}_{\mathrm{ij}}-\mathrm{LL}_{\mathrm{kj}}\right)$ Where $I \in(0,1)$

Step 11. Now GL does not update his location for a specific no. of times ( $G L_{\text {limit }}$ ), that divide the groups.

if Global Limit Count $>\mathrm{GL}_{\text {limit }}$ then set Global Limit Count $=$ 0

if Number of groups $<$ MG then

Divide the population into groups.

else

Combine all the groups to make a single group.

Update LL position.

\section{EXPERIMENTAL ANALYSIS}

The document shows the values of the ISMO in some wells Reference optimization function of the reference from $\mathrm{f} 1$ to The algorithm is compared to the basic SMO [2]. Comparison of the performance value is based on SD, ME, evaluation of the average function (AFE) and success rate (SR).

\section{A. Testing problems taken into consideration}

Problem 1 (back with six elbows): The problem of the back of the cam with six elbows has been formulated as follows: $\mathrm{F}_{1}(\mathrm{x})=\left(4-2.1 \mathrm{x}_{1}{ }^{2}+\mathrm{x}_{1}{ }^{4} / 3\right) \mathrm{x}_{1}^{2}+\mathrm{x}_{1} \mathrm{x}_{2}+\left(-4+4 \mathrm{x}_{2}{ }^{2}\right) \mathrm{x}_{2}^{2}$ The search limit [-5.5], the most suitable solution $f$ $(-0.0898,0.7126)=-1.0316$, and the acceptable error is set to $1.0 \mathrm{E}-05$. $+\mathrm{I} 3\left(\mathrm{SM}_{\mathrm{rj}}-\mathrm{SM}_{\mathrm{ij}}\right)$ Where $\mathrm{I} 1 \in(0,1), \mathrm{I} 2 \in(-1,1), \mathrm{I}$ decided by f6. The performance of the new proposal used references.

Problem 2 (Hosaki Problem): This Problem can be defined as:

$\mathrm{F}_{2}(\mathrm{x})=\left(1-8 \mathrm{x}_{1}+7 \mathrm{x}_{1}^{2}-7 \mathrm{x}_{1}^{3} / 3+\mathrm{x}_{1}^{4} / 4\right) \mathrm{x}_{2}^{2} \times \exp \left(-\mathrm{x}_{2}\right)$

The search limit $x_{1} \in[0,5]$, $x 2 \in[0,6]$, the most valid solution is $-2,3458$, the size of the problem is 2 and the acceptable error for a correct execution is set to $1,0 \mathrm{E}-06$.

Problem 3 (Rosenbrock): Rosenbrock problem is defined with dimension 30 as follows:

$$
F(x)=\sum_{\mathrm{i}=1}^{d-1} 1000(\quad)\left(\mathrm{X}_{\mathrm{i}}^{2}-\mathrm{X}_{\mathrm{i}+1}\right)^{2}+\left(1-\mathrm{X}_{\mathrm{i}}\right)
$$

The search limit $[-30,30]$, the most feasible solution is $\mathrm{f}(0)=$ 0 and acceptable the error for correct execution is set to 1.0E-01.

Problem 4 (Sphere): Sphere problem is defined as: $F(x)=\sum_{i=1}^{d} x_{\mathrm{i}}^{2}$

The search limit $[-5.12,5.12]$, the most optimal solution is $\mathrm{f}$ (0) $=0$ and acceptable the error for correct execution is set to 1.0E-01.

Problem 5 (Axis parallel hyper-ellipsoid): This problem is defined with dimension 30 as follows:

$F(x)=\sum_{i=1}^{d} i x_{\mathrm{i}}^{2}$

The search limit [-5.12,5.12], the most optimal solution is $f$ $(1,2, \ldots . \mathrm{d})=0$ and acceptable the error for correct execution is set to $1.0 \mathrm{E}-01$. The value of $\mathrm{d}$ is 30 .

Problem 6 (Ellipsoidal): Ellipsoidal problem is defined by: $F(x)=\sum_{i=1}^{d}\left(x_{\mathrm{i}}-1\right)^{2}$

The search limit [-d, d], the most optimal solution is $\mathrm{f}(0)=0$ and acceptable the error for correct execution is set to $1.0 \mathrm{E}-01$. The value of $d$ is 30 .

\section{EXPERIMENTAL ENVIRONMENT}

Using C++ programming language we use these experimental values.

- The swarm size $\mathrm{N}=100$,

- $\mathrm{MG}=10$ (max group, that limit the max no. of spider as MG

$=\mathrm{N} / 10)$,

- $\mathrm{GL}_{\text {limit }}=10$,

- $\mathrm{LL}_{\text {limit }}=3000$,

- $\operatorname{Pr} \in[0.1,0.4]$, increasing linearly with iteration.

$\mathrm{pr}_{\mathrm{G}+1}=\mathrm{pr}_{\mathrm{G}}+(0.4-0.1) / \mathrm{MIR} ; \mathrm{pr}_{1}=0.1$

where, $\mathrm{G}$ is the iteration counter, MIR is the maximum no. of iteration.

\section{EXPERIMENTAL RESULT COMPARISON}

Table 1.1 Result Comparisons

\begin{tabular}{|c|c|l|l|l|l|l|}
\hline fn & Algo & MTV & SD & ME & SR & AFE \\
\hline F1 & SMO & $-8.03 \mathrm{E}+0$ & $1.46 \mathrm{E}-05$ & $1.90 \mathrm{E}-05$ & 39 & 30783.45 \\
& ISM & 0 & $1.52 \mathrm{E}-05$ & $1.52 \mathrm{E}-05$ & 54 & 22960.92 \\
& $\mathbf{O}$ & $-9.03 \mathrm{E}+0$ & & & & \\
\hline F2 & SMO & $-5.35 \mathrm{E}+0$ & $6.28 \mathrm{E}-06$ & $5.04 \mathrm{E}-06$ & 89 & 7831.09 \\
& ISM & 0 & $6.06 \mathrm{E}-06$ & $5.59 \mathrm{E}-06$ & 94 & 3138.71 \\
& $\mathbf{O}$ & $-5.35 \mathrm{E}+0$ & & & & \\
\hline F3 & SMO & $7.20 \mathrm{E}+03$ & $8.49 \mathrm{E}-04$ & $8.62 \mathrm{E}-04$ & 36 & 27014.45 \\
& ISM & $7.20 \mathrm{E}+03$ & $3.35 \mathrm{E}-05$ & $6.85 \mathrm{E}-05$ & 62 & 023604.81 \\
& $\mathbf{O}$ & & & & & \\
\hline F4 & SMO & $4.65 \mathrm{E}+00$ & $1.03 \mathrm{E}+0$ & $1.86 \mathrm{E}+01$ & 96 & 13284.64 \\
& ISM & $6.23 \mathrm{E}-02$ & 1 & $5.23 \mathrm{E}-02$ & 98 & 11936.35 \\
& $\mathbf{O}$ & & $4.12 \mathrm{E}-01$ & & & \\
\hline
\end{tabular}




\begin{tabular}{|c|c|c|c|c|c|c|}
\hline F5 & $\begin{array}{c}\text { SMO } \\
\text { ISM } \\
\text { O } \\
\end{array}$ & $\begin{array}{l}3.00 \mathrm{E}-02 \\
3.10 \mathrm{E}-02\end{array}$ & $\begin{array}{l}6.80 \mathrm{E}-06 \\
5.00 \mathrm{E}-02\end{array}$ & $\begin{array}{l}4.12 \mathrm{E}-01 \\
4.10 \mathrm{E}-01\end{array}$ & $\begin{array}{l}70 \\
54\end{array}$ & $\begin{array}{l}4418.15 \\
15468.15\end{array}$ \\
\hline F6 & $\begin{array}{c}\text { SMO } \\
\text { ISM } \\
\text { O }\end{array}$ & $\begin{array}{l}1.02 \mathrm{E}+00 \\
3.45 \mathrm{E}-00\end{array}$ & $\begin{array}{l}8.74 \mathrm{E}-02 \\
5.32 \mathrm{E}-02\end{array}$ & $\begin{array}{l}1.02 \mathrm{E}+00 \\
3.54 \mathrm{E}-00\end{array}$ & $\begin{array}{l}80 \\
80\end{array}$ & $\begin{array}{l}40969.76 \\
28206.64\end{array}$ \\
\hline
\end{tabular}

\section{CONCLUSIONS}

This document proposes a productive variant of SMO. Using these values we improve the function evaluations. with respect to the ISMOA also we can search the viable solution to understand swarm-based intelligence algorithm. Here we update the position in the local leader stage. Using this algorithm we increase the accuracy and reliability. The average of the comparison of the convergence rate with the ISMO algorithm. This approach used to optimization algorithm m optimized for the spider monkey. We faced the 6 reference problems and the results demonstrate its superiority over the basic SMO algorithm.

\section{REFERENCES}

1. Bansal, J.C., Sharma, H., Jadon, S.S. and Clerc, M., Spider monkey optimization algorithm for numerical optimization. Memetic computing, 6(1), pp.31-47. (2014).

2. Sharma, A., Sharma, A., Panigrahi, B.K., Kiran, D. and Kumar, R., 2016. Ageist Spider Monkey Optimization algorithm. Swarm and Evolutionary Computation, 28, pp.58-77. (2016).

3. Singh, U., Salgotra, R. and Rattan, M., A Novel Binary Spider Monkey Optimization Algorithm for Thinning of Concentric Circular Antenna Arrays. IETE Journal of Re-search, pp.1-9. (2016).

4. E. Bonabeau, M. Dorigo, and G. Theraulaz. Swam intelligence:from natural to artificial systems. Oxford University press, New York, USA, 1999.

5. RL Jeanne. The evolution of the organization of work in social insects. Monitore zoologico italiano, 20(2):119-133,1986.

6. Sharma A et al (2016) Ageist spider monkey optimization algorithm. Swarm Evolut Comput 28:58-77

\section{AUTHORS PROFILE}

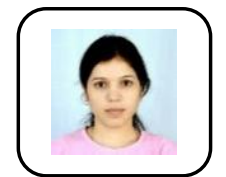

Arti Bahuguna, she is currently working as a guest teacher at the department of IT, H.N.B. Garhwal central University, Uttarakhand, India last three year. She received her $B$. tech degree from $H$. N. B. Garhwal Central University, Uttarakhand, India in 2014 and the M.tech degree in C.S.E from the GBPIET, Pauri, Uttarakahnd, India in 2016. Her current research interest includes image processing and networking. -

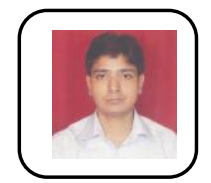

Vinay Prasad Tamta, He is currently working as Assistant Professor at Department of Information Technology, H. N. B. Garhwal Central University, Uttarakhand, India. He is in teaching from year 2012 and has 5 years of industrial experience. He got his Master in Information Technology from IIIT Allahabad (India) with specialization in Intelligent Systems and Bachelor in Information Technology from H. B. T. I. Kanpur, India.. 